\title{
QUANTITATION OF CALCIUM METABOLISM IN POSTMENOPAUSAL OSTEOPOROSIS AND IN SCOLIOSIS*
}

\author{
By F. BRONNER, L. J. RiChEllet, P. D. SAVille, J. A. NiCHOlAS, ANd J. R. COBB
}

(From the Hospital for Special Surgery and Cornell University Medical College, New York, N. Y.)

(Submitted for publication July 31, 1962; accepted March 1, 1963)

Over the past several years, work by a number of investigators [reviewed in (1)] has led to the development of a kinetic approach to the study of $\mathrm{Ca}$ metabolism. Because the studies have not been numerous and because of differences in experimental technique, results and interpretations based on them have differed. For example, some investigators (2-5) failed to find a difference in $\mathrm{Ca}$ metabolism in patients with osteoporosis as compared with normal individuals, whereas others (6) report such differences.

The purpose of this report is to present findings in persons of different ages, including women with and without osteoporosis, and young people with scoliosis, studied before and after immobilization in a plaster cast. The findings were obtained by a consistent mode of analysis applied to data collected in a uniform manner. From the results, relationships have been derived between $\mathrm{Ca}$ absorption from the intestine and $\mathrm{Ca}$ deposition in bone, and between $\mathrm{Ca}$ deposition in and removal from bone. These relationships have been used to describe $\mathrm{Ca}$ metabolism as a system of interdependent vectors in dynamic equilibrium, and this description has been applied to postmenopausal osteoporosis and the events following immobilization.

\section{METHODS}

Table I summarizes the clinical data of the experimental subjects. The patients studied included four young patients with scoliosis, aged 14 to 23 years, and seven women, aged 41 to 74 years, four of whom had been diagnosed as having postmenopausal osteoporosis, whereas two of them were clinically normal. The seventh woman (Patient 20, Table I) appeared clinically normal and free of osteoporosis, although X-ray examination of her spine led to equivocal comment by the hospital roentgenologist. Roentgenologi-

* Supported in part by grant AT(30-1)-2197, U. S. Atomic Energy Commission, U. S. Public Health Service grant A-2209, National Institutes of Health, and the National Dairy Council.

$\dagger$ Helen Hay Whitney Research Fellow. cal characteristics of osteoporosis included wedging of spinal vertebrae, ballooning of discs, and increased radiolucency of the spine. The clinical indications of scoliosis and the basis for and mode of surgical correction have been described (7-9).

The basic design of the studies was to admit a patient to the metabolic ward, measure his $\mathrm{Ca}$ balance, and carry out kinetic experiments with $\mathrm{Ca}^{45}$ or $\mathrm{Ca}^{47}$ at predetermined periods (see Appendix for details). Kinetic studies of the patients with scoliosis were generally done while the patients were ambulatory, 2 to 3 weeks after they had been placed in plaster jackets equipped with turnbuckles and while still in these jackets, and some months after they had recovered from an operation for spinal arthrodesis. Balance periods (lasting 15 to 21 days) encompassed the kinetic study periods (lasting 6 to 9 days). Patients with osteoporosis, or control subjects were studied according to a similar protocol, i.e., during control periods (without any treatment) and during periods when they were undergoing some treatment. The effect of various treatments will be the subject of a later report.

Before admission, patients were interviewed by a dietitian and also asked to keep a diet diary for a few days. On the basis of this information, a diet was devised that conformed to the usual nutrient intake of the subject. Diets consisted of three different individual menus that were rotated in order. Intake was controlled by weighing duplicate portions of all meals eaten and analyzing samples of the diet pools. When leftovers occurred, they were weighed, and the equivalent quantity was removed from the duplicate diet before pooling and subsequent analysis. The amounts involved were less than $5 \%$ of the $\mathrm{Ca}$ intake. While a kinetic study was in progress, urine and stool collections were on a 24-hour basis; otherwise, pooled 3-day (urine) or 6-day (stool) samples were collected.

$\mathrm{Ca}$ analysis was done by oxalate precipitation and titration with perchloratoceric acid (10). Urine was analyzed for $\mathrm{Ca}$ directly. The error of replicate analyses was held to $\pm 3 \%$ SD. Feces and food were homogenized and converted to ash before analysis. The error of replicate analyses including conversion to ash was held to $\pm 5 \%$ SD. $\mathrm{Ca}^{45}$ analysis was done on samples of $\mathrm{Ca}$ oxalate (11) counted in an automatic flow counter (10). $\quad \mathrm{Ca}^{47}$ analysis was done in a scintillation well counter connected to a pulse-height analyzer and automated print-out device. The counting error on replicate samples was held to $\pm 5 \% \mathrm{SD}$

Data were analyzed according to the second of the two simplified methods, scheme I, previously described in detail (1). Specific activity data were expressed as the percent- 
TABLE I

Summary of pertinent clinical data

\begin{tabular}{|c|c|c|c|c|}
\hline Patient & Age & Sex & $\mathbf{W t}$ & Clinical diagnosis and comments \\
\hline no. & years & & kg & \\
\hline 1 & 41 & $\mathbf{F}$ & 49 & Normal premenopausal woman \\
\hline 2 & 59 & $\mathbf{F}$ & 52 & $\begin{array}{l}\text { Normal menopause } 10 \text { years ago; asymptomatic } \\
\text { gallstones }\end{array}$ \\
\hline 3 & 17 & $\mathbf{M}$ & 76 & Scoliosis, congenital; idiopathic hypercalciuria \\
\hline 4 & 16 & $\mathrm{~F}$ & 48 & Scoliosis, congenital \\
\hline 7 & 74 & $\mathbf{F}$ & 54 & $\begin{array}{l}\text { Osteoporosis; hysterectomy } 34 \text { years ago; fractured } \\
\text { ankle and neck of femur; number of compressions } \\
\text { increased over the past } 5 \text { years of observation }\end{array}$ \\
\hline 8 & 14 & $\mathbf{F}$ & 43 & Scoliosis, idiopathic \\
\hline 12 & 23 & $\mathbf{M}$ & 68 & Scoliosis, idiopathic \\
\hline 14 & 55 & $\mathbf{F}$ & 49 & $\begin{array}{l}\text { Osteoporosis; menopause } 14 \text { years ago; spinal } \\
\text { arthrodesis } 1 \text { year ago }\end{array}$ \\
\hline 18 OPD & 69 & $\mathrm{~F}$ & 56 & $\begin{array}{l}\text { Osteoporosis; menopause } 23 \text { years ago; on Nilevar* } \\
1 \text { or } 2 \times \text { daily for } 8 \text { months before admission, } \\
\text { but not while on study }\end{array}$ \\
\hline 20 & 57 & $\mathbf{F}$ & 59 & $\begin{array}{l}\text { Osteoporosis?; hysterectomy } 16 \text { years ago; fibroids; } \\
\text { cholecystectomy } 7 \text { years ago }\end{array}$ \\
\hline 21 & 61 & $\mathbf{F}$ & 58 & Osteoporosis; menopause 20 years ago \\
\hline
\end{tabular}

* 17 $\alpha$-Ethyl-19-nortestosterone.

age administered dose per milligram Ca. Parameters of $\mathrm{Ca}$ metabolism were calculated in milligrams $\mathrm{Ca}$ (per day). The following symbols are used (see Figure 1): $P=$ pool size, $v_{T}=$ rate of loss from pool, $v_{u}=$ urinary Ca output, $v_{f}=$ endogenous fecal Ca output, $v_{F}=$ total fecal Ca output, $v_{a}=\mathrm{Ca}$ absorbed, $v_{i}=\mathrm{Ca}$ ingested, $v_{o_{+}}=$bone formation, $v_{o_{-}}=$bone resorption, $\Delta=\mathrm{Ca}$ balance, and $\alpha=$ percentage of $\mathrm{Ca}$ absorbed.

\section{RESULTS}

The results for the normal and osteoporotic women are summarized in Table II, and for the young people with scoliosis, in Table III. Both tables show the balance data $\left(v_{i}, v_{u}, v_{F}\right.$, and $\left.\Delta\right)$. Isotope data from which the remaining parameters $\left(P, v_{T}, v_{f}, v_{o+}, v_{o_{-}}, v_{2}\right.$, and $\left.\alpha\right)$ were cal-

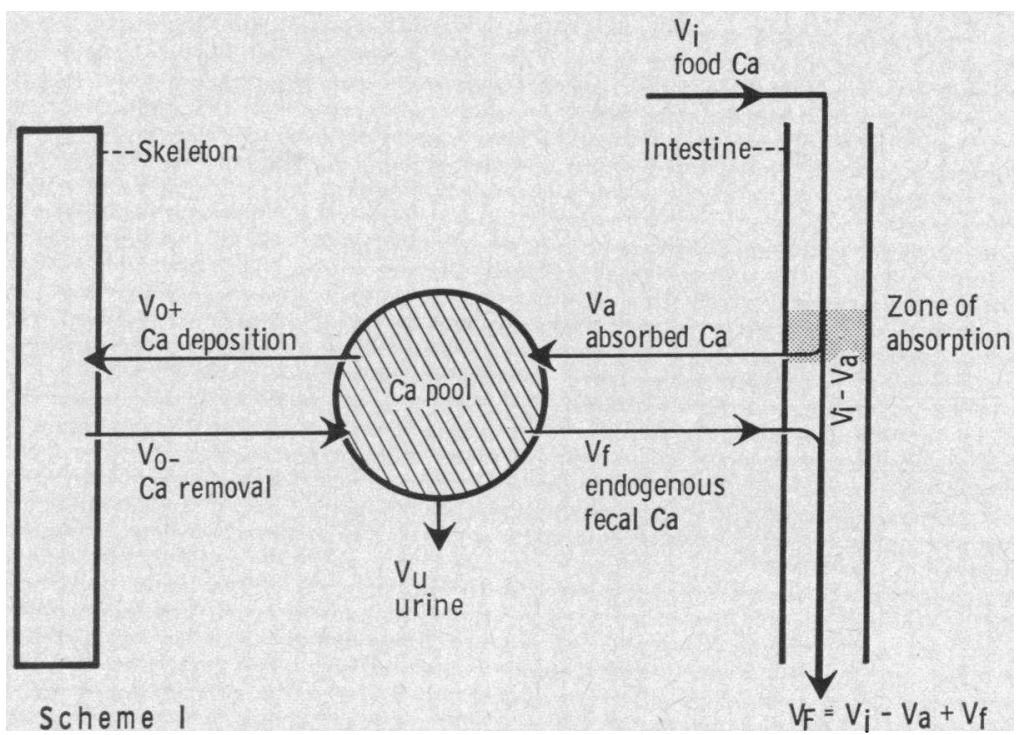

Fig. 1. SCheme of Ca metabolism depicting parameters eValuated in THESE STUDIES. 


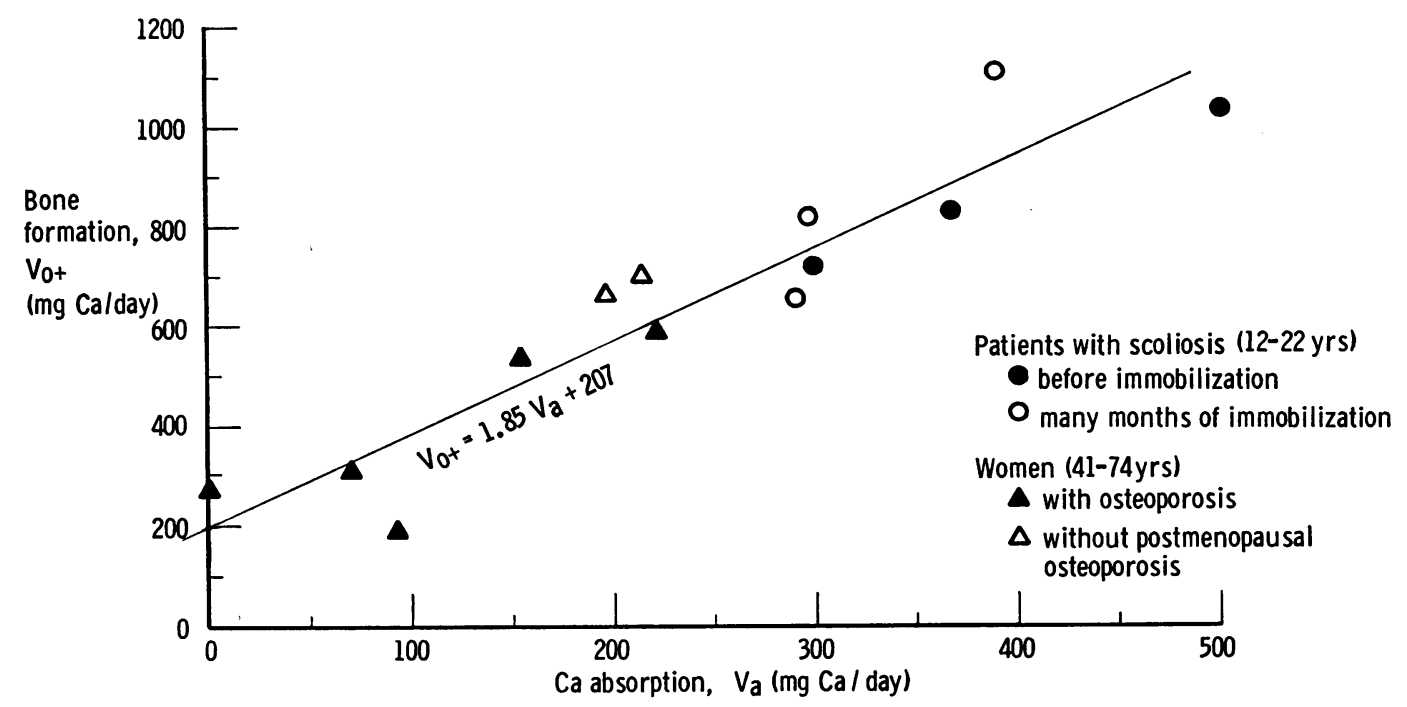

Fig. 2. Relationship between Ca absorption and bone formation. The equation was derived by the method of least squares and is based on all studies (Tables II and III) except 3B, 3D, 3F, 4D, 8C, and $12 \mathrm{D}$.

culated are shown in the Appendix. The specific activity of the pool between 36 and 144 hours after injection of the isotope was determined from urine measurements. The equations for the time-course of the specific activity were derived by the method of least squares; the error of the individual values for slope and intercept was $\pm 5 \%$.

The question arises whether relationships exist between the parameters of $\mathrm{Ca}$ metabolism in addition to those used to resolve the scheme. To put such relationships in evidence, we excluded all studies where either therapy had been instituted or a pathological condition existed. These conditions evidently could affect the system in dynamic equilibrium so as to con- strain one or several parameters and produce a situation where normal regulation of $\mathrm{Ca}$ metabolism no longer prevails. The following studies were excluded: $3 \mathrm{~B}, 3 \mathrm{D}$, and $3 \mathrm{~F}$ because the patient had idiopathic hypercalciuria, and $4 \mathrm{D}$, $8 \mathrm{C}$, and $12 \mathrm{D}$ because, as will be discussed below, the magnitudes of the parameters measured shortly after immobilization of these patients do not represent their norms.

Two relationships emerged; in one, $\mathrm{Ca}$ absorption and bone formation (in terms of unidirectional Ca loss from the pool) were linked by a linear relationship; in the other, a linear relation was found to exist between bone formation and bone resorption (expressed in terms of unidirectional Ca return to the pool).

TABLE II

Ca metabolism data in women with and without postmenopausal osteoporosis*

\begin{tabular}{|c|c|c|c|c|c|c|c|c|c|c|c|}
\hline Study & $P$ & $v_{T}$ & $v_{u}$ & $v_{F}$ & $v_{f}$ & $v_{o+}$ & $v_{0-}$ & $v_{i}$ & $\Delta$ & $v_{a}$ & $\alpha$ \\
\hline & $m g C a$ & & \multicolumn{7}{|c|}{ milligrams Ca/day } & & $\%$ \\
\hline $\begin{array}{l}21 \mathrm{~A} \\
14 \mathrm{~A} \\
20 \mathrm{~B} \\
18 \mathrm{OPD} \\
7 \mathrm{~A} \\
1 \mathrm{~B} \\
2 \mathrm{~A}\end{array}$ & $\begin{array}{l}2,185 \\
3,448 \\
2,165 \\
2,089 \\
3,086 \\
3,424 \\
4,950\end{array}$ & $\begin{array}{l}406 \\
584 \\
478 \\
922 \\
792 \\
855 \\
998\end{array}$ & $\begin{array}{r}104 \\
245 \\
100 \\
263 \\
66 \\
171 \\
206\end{array}$ & $\begin{array}{r}1,041 \\
993 \\
349 \\
298 \\
707 \\
558 \\
495\end{array}$ & $\begin{array}{r}121 \\
70 \\
75 \\
123 \\
139 \\
33 \\
94\end{array}$ & $\begin{array}{l}181 \\
269 \\
303 \\
536 \\
587 \\
651 \\
698\end{array}$ & $\begin{array}{l}313 \\
584 \\
408 \\
768 \\
569 \\
658 \\
783\end{array}$ & $\begin{array}{r}1,013 \\
923 \\
344 \\
329 \\
791 \\
722 \\
616\end{array}$ & $\begin{array}{r}-132 \\
-315 \\
-105 \\
-232 \\
+\quad 18 \\
-\quad 7 \\
-\quad 85\end{array}$ & $\begin{array}{r}93 \\
0 \\
70 \\
154 \\
223 \\
197 \\
215\end{array}$ & $\begin{array}{r}9 \\
0 \\
20 \\
47 \\
28 \\
27 \\
35\end{array}$ \\
\hline
\end{tabular}

* Studies listed in ascending order of $v_{o+.} \quad P=$ pool size, $v_{T}=$ rate of loss from $P, v_{u}=$ urinary Ca output, $v_{F}=$ total fecal Ca output, $v_{f}=$ endogenous fecal $\mathrm{Ca}$ output, $v_{o_{+}}=$bone formation, $v_{o_{-}}=$bone resorption, $v_{i}=\mathrm{Ca}$ ingested, $\Delta=\mathrm{Ca}$ balance, $V_{a}=\mathrm{Ca}$ absorbed, and $\alpha=$ percentage of $\mathrm{Ca}$ absorbed. 
TABLE III

Ca metabolism data in patients with scoliosis*

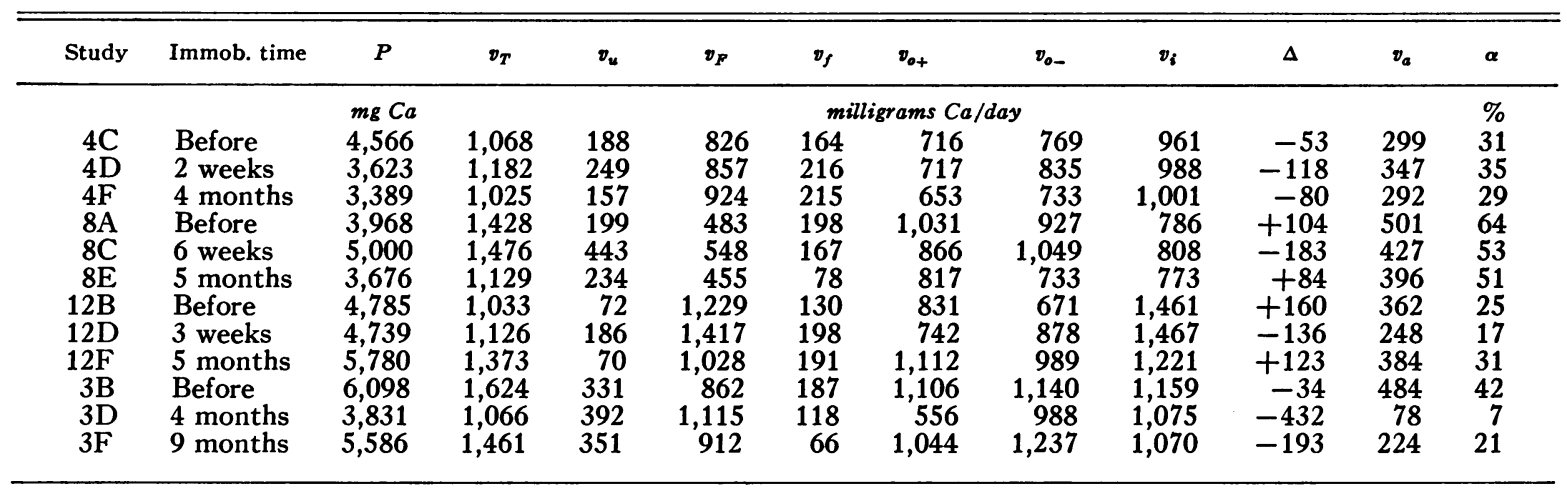

* Symbols as in Table II.

Figure 2 pictures the relationship between $\mathrm{Ca}$ absorption and bone formation: $v_{o+}=1.85 v_{a}$ +207 (Equation 1), in milligrams Ca per day. The equation was derived by the method of least squares. The value of the slope (1.85) is highly significant $(p<0.01)$ as tested by comparing the linear regression variance with the deviation from this regression ( $\mathrm{F}$ test). The $90 \%$ confidence limits of the slope are 2.27 and 1.43 . The $90 \%$ confidence limits of the intercept are 322 and $92 \mathrm{mg}$ Ca per day. Equation 1 indicates that $v_{o+}$ and $v_{a}$ varied in the same direction and that $v_{o+}$ increased more rapidly than $v_{a}$. In- spection of Figure 2 reveals that the older patients formed less bone and absorbed less $\mathrm{Ca}$, whereas the values for the younger persons are located in the upper part of the curve, i.e., they formed more bone and also absorbed more Ca.

Figure 3 pictures the relationship between bone formation and bone resorption in these patients; the equation was derived by the method of least squares: $v_{o_{-}}=0.61 v_{o_{+}}+298$ (Equation 2). The value of the slope $(0.61)$ is highly significant $(\mathrm{p}<0.01)$ as tested by comparing the linear regression variance with the deviation from this regression ( $F$ test). The

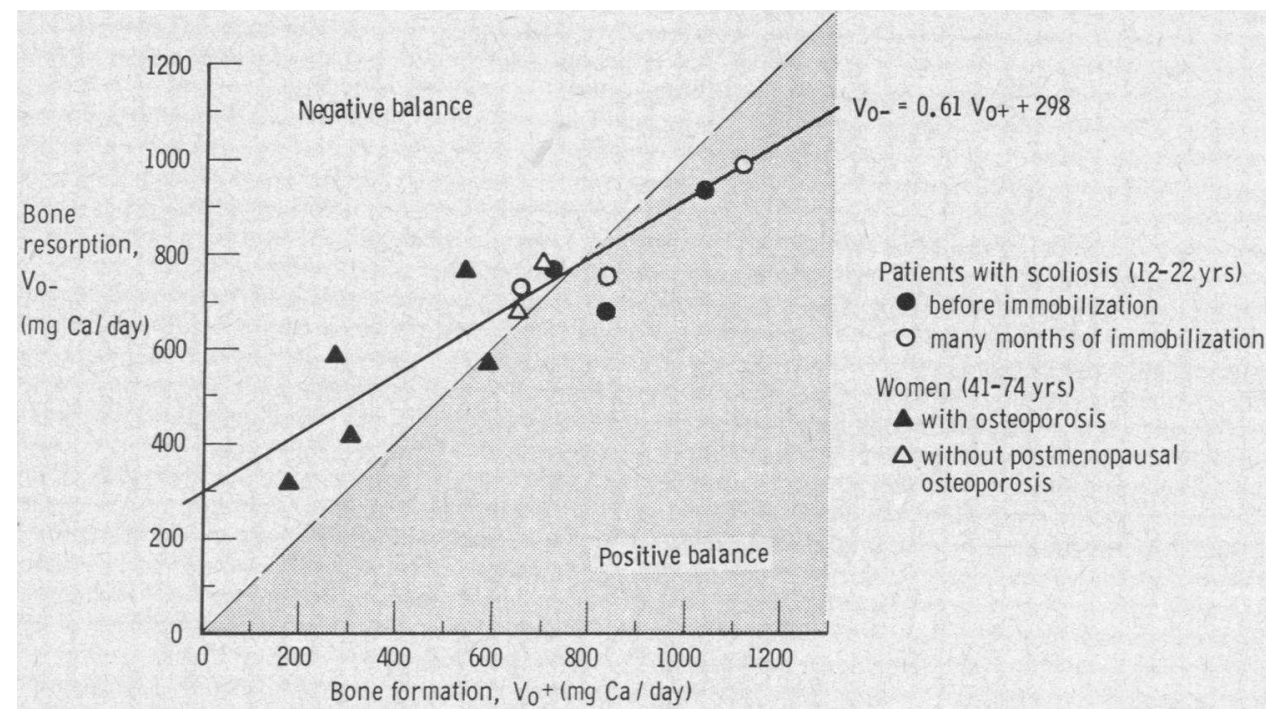

Fig. 3. RELATIONSHIP BETWEEN BONE FORMATION AND BONE RESORPTION. The equation was derived by the method of least squares and is based on the same studies as Figure 2 . The dashed line represents $v_{o_{+}}=v_{o_{-}}$. The difference between the two lines is the $\mathrm{Ca}$ balance. 

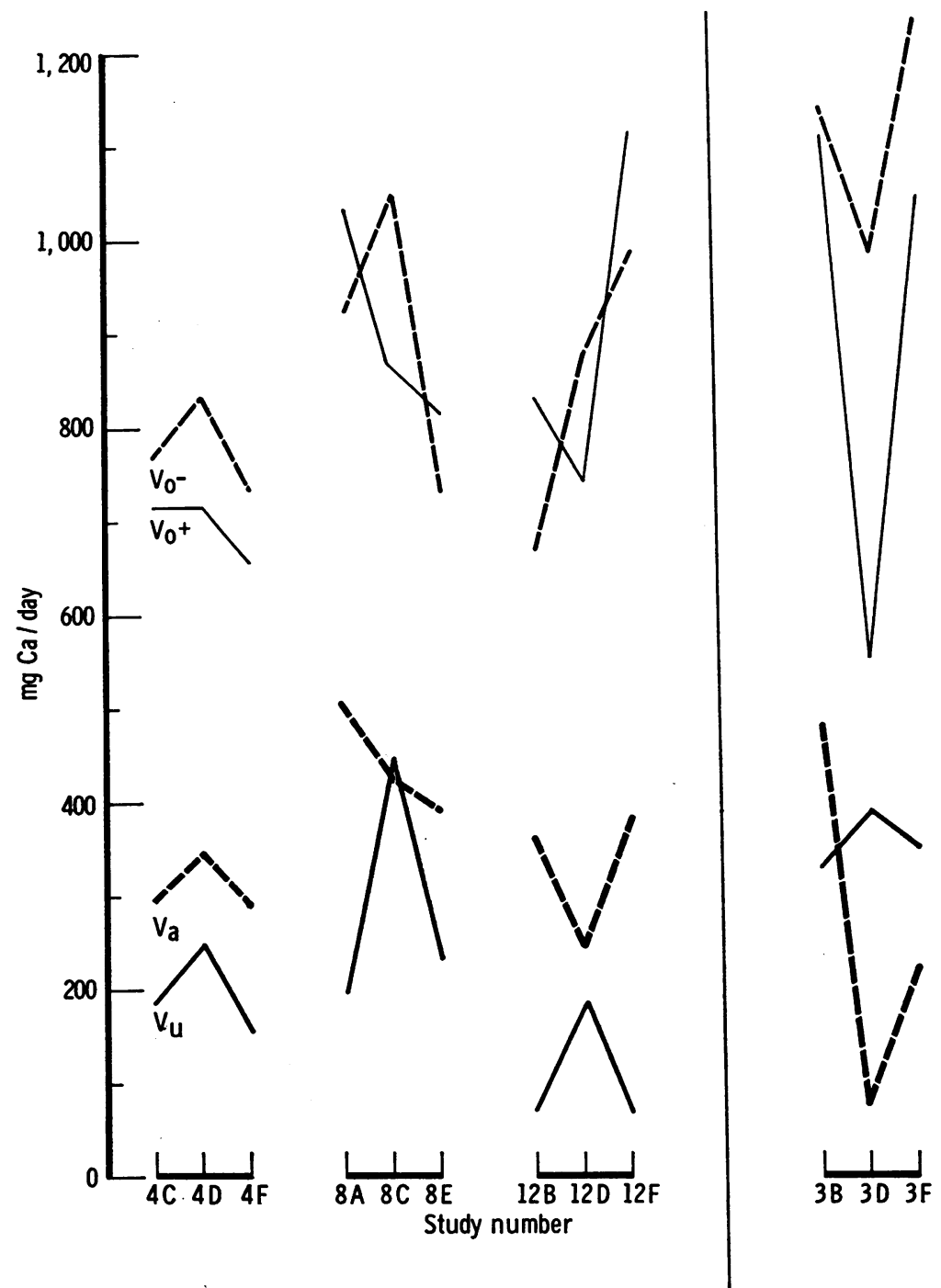

Fig. 4. EFFECT OF IMMOBILIZATION IN A PLASTER CAST ON CALCIUM METABOLISM IN FOUR PATIENTS WITH SCOLIOSIS. 'Patient 3 had idiopathic hypercalciuria. For explanation of studies, see Table III; $v_{u}=$ urinary Ca excretion, $v_{a}=\mathrm{Ca}$ absorption, $v_{o_{+}}=$bone formation, and $v_{o_{-}}=$bone resorption.

$90 \%$ confidence limits of the slope are 0.79 and 0.43. The $90 \%$ confidence limits of the intercept are 417 and $179 \mathrm{mg}$ Ca per day.

Equation 2 indicates that $v_{o+}$ and $v_{o-}$ varied in the same direction, that $v_{o-}$ increased less rapidly than $v_{o+}$, and that $v_{o_{+}}$was greater than $v_{o_{-}}$at values over $765 \mathrm{mg}$ per day. This means that the probability of a person being in positive $\Delta$ when his $v_{0+}$ exceeded $765 \mathrm{mg}$ Ca per day was greater than when it was below that value. In the latter case, he would be expected to be in negative $\Delta$. This is shown graphically on Figure 3 , where the dashed line represents the situation that would prevail if $v_{o+}$ always equaled $v_{o-}$. Consequently, the difference between the experimental line determined by least squares and the line representing a zero $\Delta\left(v_{o+}=v_{o-}\right)$ is the predicted $\Delta$. Inspection of Figure 3 also reveals that values measured for the younger persons are distributed along the upper portion of the curve, whereas those for the older persons are along the lower half. 
The effect of immobilization in a plaster cast on certain of the parameters is shown graphically in Figure 4. The left-hand part of Figure 4 deals with three of the patients with scoliosis whose $\mathrm{Ca}$ metabolism appeared normal; on the right are pictured the changes in the patient with scoliosis who also had idiopathic hypercalciuria. In all four patients immobilization at first led to increased $v_{u}$, but after the patients had been in the cast for many months, values for $v_{u}$ returned to their normal levels (12). In the three patients with normal $\mathrm{Ca}$ metabolism, the changes in $v_{a}$ paralleled qualitatively the changes in $v_{o+}$. This suggests that the relationship represented by Equation 1 was not altered significantly as a result of immobilization; indeed, all values for $v_{o+}$ and $v_{a}$ fall within the error range $( \pm 1 \mathrm{SE})$ of Equation 1. This parallelism between $v_{o+}$ and $v_{a}$ also prevailed for Patient 3 , but his values were outside the error range.

On the basis of Equation 2, $v_{o+}$ and $v_{o-}$ would be expected to vary in parallel. Figure 4 reveals that shortly after immobilization, $v_{o-}$ increased in the three patients with normal $\mathrm{Ca}$ metabolism, whereas $v_{o+}$ either decreased or remained the same. Qualitatively, therefore, the direction of change in these two parameters was different from normal. After the patients had been in the cast for some months, the relationship between $v_{o_{+}}$and $v_{o_{-}}$tended to return to what it was before immobilization, although the level was not always the same.

From the data reported here, no clear-cut distinction was possible between the control and the osteoporotic subjects, even though the parameters of the latter group tended to be low relative to the range of values observed in the entire group studied here (Tables II and III, Figures 2 and 3).

\section{DISCUSSION}

Dynamics of $\mathrm{Ca}$ metabolism. The various parameters of $\mathrm{Ca}$ metabolism measured and the supplementary relationships derived describe a complex system in a state of dynamic equilibrium whose vectors appear interdependent. The state of $\mathrm{Ca}$ metabolism of each subject studied has been defined in terms of this system, and some data, like $\mathrm{Ca}$ retention, have been expressed in terms of their component rates and therefore have assumed greater physiological significance.

Because it was possible to define two independent relationships for $v_{o+}, v_{o_{-}}$, and $v_{a}$ (Equations 1 and 2), the entire system can be described for this group of subjects as a function of $v_{o+}$ : $\Delta=0.39 v_{o+}-298$ and $v_{u}+v_{f}=0.15 v_{o+}+186$ (Equations 3 and 4). Equation 3 is obtained by substituting Equation 2 in the relationship $\Delta=v_{o_{+}}-v_{o_{-}}$, and Equation 4 by combining Equations 1 and 2 and substituting in the relationship $v_{u}+v_{f}+v_{o+}=v_{a}+v_{o-}$. For derivation of these relationships, see (1). Equations 3 and 4 are based on the same experimental values as Equations 1 and 2. The degree, however, to which the individual experimental points deviate from the theoretical straight line is a function of the error inherent in the particular measurement, i.e., $\Delta$ or $\left(v_{u}+v_{f}\right)$.

Equation 1 indicates that $v_{o+}$ and $v_{a}$ varied in the same direction, but does not indicate which was the independent variable. Another possibility is that both $v_{o+}$ and $v_{a}$ were functions of a third, independent factor. The possibility that under certain circumstances an insufficient amount of $\mathrm{Ca}$ may be absorbed to satisfy a relationship between $v_{o+}$ and $v_{a}$ has a bearing on the concept of $\mathrm{Ca}$ requirement. It is evident from Equation 1 that if $v_{o+}$ is to be maintained at a certain level $k, v_{i}$ cannot drop below $(k-a) / b$, if $\alpha=100 \%$ and where $a$ is the intercept and $b$ the slope for an equation such as Equation 1. Therefore, if $v_{o+}$ were known for persons of varying ages and states, minimal $\mathrm{Ca}$ requirements could be set up. Tables II and III indicate that no obvious relationship existed betwen $v_{i}$ and $v_{a}$, with $\alpha$ varying between 0 and $64 \%$. Hence it proved impossible to derive a relationship between $v_{i}$ and $v_{o+}$ for the group of subjects studied here.

Equation 2 indicates that both skeletal metabolic processes, $v_{o_{+}}$and $v_{o_{-}}$, varied in the same direction. It does not indicate whether $v_{o+}$, or $v_{o-}$ was the independent variable, or whether both were functions of a third factor. Since in our system of analysis (1) $\Delta$ is the difference between $v_{o_{+}}$and $v_{o_{-}}$, it follows from Equation 2 that $\Delta$ is a direct function of the intensity of $v_{o+}$, described for our subjects by Equation 3. If, 
therefore, the relationships described by Equations 1 through 4 are maintained, ila negative $\Delta$ will result if skeletal turnover is of relatively low intensity. In our group of patients, the older women who had a skeletal turnover of relatively low intensity fell into that category, although no clear-cut distinction could be made between the women with and those without osteoporosis. Nevertheless, in the light of the system of $\mathrm{Ca}$ metabolism just discussed, postmenopausal osteoporosis could be described as a condition where the intensity of most of the various parameters of $\mathrm{Ca}$ metabolism tends to be relatively low. Such a description implies that treatment of postmenopausal osteoporosis might profitably aim at increasing the turnover of the bone mineral. Whether this can be attained by increasing $v_{a}$ as suggested by Nordin (13), or only by directly augmenting $v_{o+}$ requires further study.

Immobilization in a plaster cast resulted, in all four patients, in a transitory change in the relationship of $v_{o+}$ to $v_{o-}$, so that the difference between these two rates became larger than before and 4 to 9 months after immobilization. If this change were the result of an effect on skeletal metabolism without compensating changes in the remainder of the system, the pool would expand appreciably. If $\mathrm{Ca}$ homeostasis involves keeping $P$ relatively constant, either losses from the pool must augment or entries diminish. $\mathrm{Pa}$ tients 4,8 , and 12 increased their $v_{u}$ considerably, altering $v_{a}$ relatively little. Patient 3 , perhaps because he had idiopathic hypercalciuria, did not increase his $v_{u}$ by much, but his $v_{a}$ dropped profoundly. Undoubtedly a complete description of $\mathrm{Ca}$ homeostasis is more complex than the preceding statements imply. Nevertheless, these findings illustrate the different possibilities of regulating $\mathrm{Ca}$ metabolism, e.g., renal against intestinal control.

The fact that many months after these patients had been placed in the casts, their Ca metabolism tended to return to their respective norms implies that no permanent alteration had resulted from immobilization and spinal arthrodesis.

\section{SUMMARY}

By a combination of balance and isotope techniques, the following parameters of $\mathrm{Ca}$ metabolism were measured: pool size $(P)$, rate of loss from pool $\left(v_{T}\right)$, urinary excretion $\left(v_{u}\right)$, fecal excretion $\left(v_{F}\right)$, intake $\left(v_{i}\right)$, endogenous fecal Ca $\left(v_{f}\right)$, absorption $\left(v_{a}\right)$, balance $(\Delta)$, bone formation $\left(v_{o+}\right)$, and bone resorption $\left(v_{o_{-}}\right)$. The subjects were two normal women and five women with postmenopausal osteoporosis, aged 41 to 74 years, and four patients with scoliosis, aged 12 to 22 years. The latter were studied before, shortly after, and many months after immobilization in plaster casts.

From these data, the following relationships were derived: 1) $v_{o+}=1.85 v_{a}+207$ and 2) $v_{o-}=0.61 v_{o+}+298$, and hence, 3) $\Delta=0.39 v_{o+}$ -298 and 4) $v_{u}+v_{f}=0.15 v_{o+}+186$, in milligrams $\mathrm{Ca}$ per day. These equations indicate that in our patients all vectors of $\mathrm{Ca}$ metabolism could be expressed as a function of bone formation.

On the basis of these relationships, it appeared that the negative $\mathrm{Ca}$ balance observed in the older women was due to the low intensity of the various vectors of $\mathrm{Ca}$ metabolism, without clearcut distinction between the subjects with and without osteoporosis. Conversely, in the young patients with scoliosis, the negative balance incident to treatment by immobilization was associated with vectors of relatively high intensity whose relationships were altered temporarily.

\section{ACKNOWLEDGMENTS}

We thank Dr. J.-P. Aubert for many fruitful discussions and for his help in evaluating the data. We gratefully acknowledge the nursing supervision and care of Mary Jeanne Clapp, Marion McTernan, Barbara Bauer, Eva Brewer, and Hazel Wilkins; the skillful dietary supervision and planning of B. Sue Keffer; and the technical assistance of Ellin Burgess, Vida Gintoff, Frances Gruen, Vivienne Leon, Nannette Mann, and Carol Wang. Dr. Konstantin Veliskakis helped manage the patients with scoliosis.

\section{APPENDIX}

Together with the balance data $\left(v_{u}, v_{F}, v_{i}\right.$, and $\left.\Delta\right)$ reported in Tables II and III, the kinetic data listed here allow calculation of all remaining parameters for each study. The various methods of analyzing the data have been presented in detail (1). Most of the studies were done after iv injection of radioactive calcium and the results analyzed by the second of the simplified methods described in (1).

When radiocalcium was given intravenously, 5 to $10 \mu \mathrm{c}$ $\mathrm{Ca}^{45}$ as $\mathrm{CaCl}_{2}$ in sterile isotonic saline solution was injected into the arm vein. The $\mathrm{Ca}^{45}$ was obtained as $\mathrm{Ca}-45-\mathrm{P}-2^{1}$

${ }^{1}$ U. S. Atomic Energy Commission, Oak Ridge, Tenn. 
and was suitably diluted and sterilized in a rubber-capped vial. When $\mathrm{Ca}^{47}$ was used, 15 to $30 \mu \mathrm{c} \mathrm{Ca}{ }^{47}$ as $\mathrm{CaCl}_{2}$ was administered; it was diluted and prepared like the $\mathrm{Ca}^{45}$. Standards were prepared by diluting to $100 \mathrm{ml}$ with $\mathrm{CaCl}_{2}$ solution $(0.04 \mathrm{mg} \mathrm{Ca}$ per $\mathrm{ml})$ an identical dose, withdrawn with the same syringe used for iv injection just before injection into the patient.

When the isotope was given by mouth, 10 to $20 \mu \mathrm{c} \mathrm{Ca} \mathrm{Ca}^{45}$ as $\mathrm{CaCl}_{2}$ was injected into a glass of 150 to $180 \mathrm{~g}$ milk; the milk was thoroughly stirred and usually left in the refrigerator overnight. The patient drank the milk at midmorning, and the appropriate amount of $\mathrm{Ca}$, or milk, or both was taken into account when preparing that day's menu. The standard was prepared like that in iv studies.

In the table below, $A_{4}$ and $a_{4}$ are the two experimental parameters of Equation A1, derived from urine specific activity values between 36 and 144 hours after isotope injection: $R_{8}=A_{4} e^{-a_{4} t}$, where $R_{8}=$ the specific activity of the pool (\% dose per $\mathrm{mg} \mathrm{Ca}$ ) and $t=$ time in days. $R_{u}$ and $R_{F}$ are the amounts of radioactivity recovered in the urine and feces, respectively, during a period equivalent to 0 to 6 days; both are expressed in $\%$ dose.

In all these studies, $v_{f}$ was calculated by applying

$$
\left.\left.v_{f}=v_{u}\left(R_{F}\right]_{t 1}^{t_{2}} / R_{u}\right]_{t 1} t_{2}\right)
$$

In study $4 \mathrm{C}, R_{F}$ was recovered from days 0 to 4 only. Since radioactivity was administered by iv injection, results were analyzed by the simplified method; $v_{f}$ was not calculated as above, but by:

$$
\left.v_{f}=v_{T} \times\left(R_{F}\right]_{0}^{4} /\left[1-e^{-a_{4} t}\right]_{0}^{4}\right) .
$$

The experimental data were: $A_{4}=0.0219, a_{4}=0.2340$, $\left.R_{u}\right]_{0}{ }^{6}=16.2$, and $\left.R_{F}\right]_{0}{ }^{4}=9.4$.

In study $14 \mathrm{~A}$, where $R_{F}$ was known only for days 1 to 5 , the data were treated as in study $4 \mathrm{C}$; radioactivity was administered by iv injection and the experimental data were: $\left.A_{4}=0.0290, a_{4}=0.1694, R_{u}\right]_{0}{ }^{6}=30.1$, and $\left.R_{F}\right]_{1}{ }^{5}=5.0$.

\begin{tabular}{cccrr}
\hline \hline Study & \multicolumn{1}{c}{$A_{\boldsymbol{4}}$} & $\boldsymbol{a}_{\boldsymbol{4}}$ & \multicolumn{1}{c}{$\boldsymbol{R}_{\boldsymbol{u}}$} & \multicolumn{1}{c}{$\boldsymbol{R}_{\boldsymbol{F}}$} \\
\hline 1B & 0.0292 & 0.2496 & 18.6 & 3.5 \\
2A & 0.0202 & 0.2016 & 17.5 & 5.2 \\
3B & 0.0164 & 0.2664 & 19.3 & 10.9 \\
3D & 0.0261 & 0.2784 & 37.5 & 11.2 \\
3F & 0.0179 & 0.2616 & 24.1 & 4.5 \\
4D & 0.0276 & 0.3264 & 23.7 & 20.8 \\
4F & 0.0295 & 0.3024 & 13.7 & 18.8 \\
7A & 0.0324 & 0.2568 & 5.5 & 11.6 \\
8A & 0.0252 & 0.3600 & 17.0 & 16.9 \\
8C & 0.0200 & 0.2952 & 34.3 & 13.0 \\
8E & 0.0272 & 0.3072 & 24.1 & 8.0 \\
12B & 0.0209 & 0.2160 & 5.6 & 5.9 \\
12D & 0.0211 & 0.2376 & 14.1 & 15.2 \\
12F & 0.0173 & 0.2376 & 4.2 & 11.4 \\
20B & 0.0462 & 0.2208 & 15.7 & 11.1 \\
\hline
\end{tabular}

Study 18 OPD was analyzed by the radioactivity balance method (1): radioactivity was administered by mouth. The experimental data were: $A_{4}=0.0224, a_{4}=0.4416$, $\left.R_{u}\right]_{0}{ }^{6}=11.8$, and $\left.R_{F}\right]_{0}{ }^{6}=58.7$.

In study $21 \mathrm{~A}$, radioactivity was also administered by mouth. Results were analyzed by the simplified method, and $v_{f}$ was calculated by Equation A2. In this case, $R_{f}$ (which differs from $R_{F}$ in an oral experiment) was obtained by analyzing the monoexponential portion of the feces specific activity curve. The experimental data were: $\left.A_{4}=0.00421, \quad a_{4}=0.1860, R_{u}\right]_{2}{ }^{6}=0.903$, and $\left.R_{f}\right]_{2}{ }^{6}$ $=1.051$.

\section{REFERENCES}

1. Aubert, J.-P., F. Bronner, and L. J. Richelle. Quantitation of calcium metabolism. Theory. J. clin. Invest. 1963, 42, 885.

2. Nordin, B. E. C. Investigation of bone metabolism with ${ }^{47} \mathrm{Ca}-\mathrm{a}$ preliminary report. Proc. roy. Soc. Med. 1959, 52, 351.

3. Heaney, R. P., and G. D. Whedon. Radiocalcium studies of bone formation rate in human metabolic bone disease. J. clin. Endocr. 1958, 18, 1246.

4. Dow, E. C., and J. B. Stanbury. Strontium and calcium metabolism in metabolic bone diseases. J. clin. Invest. 1960, 39, 885.

5. Fraser, R., M. Harrison, and K. Ibbertson. The rate of calcium turnover in bone. Measurement by a tracer test using stable strontium. Quart. J. Med. 1960, 29, 85.

6. Eisenberg, E., and G. S. Gordan. Skeletal dynamics in man measured by nonradioactive strontium. J. clin. Invest. 1961, 40, 1809.

7. Cobb, J. R. Treatment of scoliosis. Conn. med. J. 1943, 7, 467.

8. Cobb, J. R. Outline for the study of scoliosis. Amer. Acad. orthop. Surg. 1948, 5, 261.

9. Cobb, J. R. Spine arthrodesis in the treatment of scoliosis. Bull. Hosp. Jt. Dis. 1958, 19, 187.

10. Bronner, F., R. S. Harris, C. J. Maletskos, and C. E. Benda. Studies in calcium metabolism. Effect of food phytates on calcium-45 uptake in children on low-calcium breakfasts. J. Nutr. 1954, 54, 523.

11. Bronner, F., and N. A. Jernberg. Simple centrifugal filtration assembly for preparation of solid samples for radioassay. Analyt. Chem. 1957, 29, 462.

12. Whedon, G. D., and E. Shorr. Metabolic studies in paralytic acute anterior poliomyelitis. II. Alterations in calcium and phosphorus metabolism. J. clin. Invest. 1957, 36, 966.

13. Nordin, B. E. C. Osteoporosis and calcium deficiency. Proc. Nutr. Soc. 1960, 19, 129. 